\title{
Mode of vaginal delivery in breech presentation and perinatal outcome
}

\author{
Analena Gregorić 1 (1) , Ana Benčić 1 (1), Dubravko Habek2, 3(1) \\ ${ }^{1}$ School of Medicine, University of Zagreb, Croatia \\ ${ }^{2}$ Department of Obstetrics and Gynecology, Clinical Hospital Sveti Duh, Zagreb, Croatia \\ ${ }^{3}$ Catholic University of Croatia, Zagreb, Croatia
}

\begin{abstract}
Objectives: To compare a perinatal outcome in breech presentation depending on different modes of vaginal breech delivery (VBD).

Material and methods: Over the course of 13 years (2005-2018), perinatal outcome of newborns was compared among 98 singleton pregnancies (64 term pregnancies and 34 preterm pregnancies) completed with VBD divided into six groups depending on the mode of delivery used (Bracht, Müller, Thiessen, classical arm release, Mauriceau-Levret-Veit-Smellie (MLVS), and Vermelin's spontaneous vaginal delivery). Also, maternal demographic parameters were observed.

Results: Of 98 singleton pregnancies, the most frequently used mode was Thiessen (35.71\%), followed by MLVS technique (25.51\%), Bracht (22.45\%), Vermelin (13.27\%), classical arm release (2.04\%) and Müller (1.02\%). Newborns with Apgar score $\leq 7$ at $5 \mathrm{~min}$. were transferred to the neonatal intensive care unit (NICU), which included $15.31 \%$ of newborns (total 15 newborns: 1 term and 14 preterm newborns). The incidence of episiotomy was 63.27\%. Seventy-point five percent of women included in the study were $\leq 35$ years of age, and $37.76 \%$ were multiparas. Delivery was induced in $7.14 \%$ cases. Conclusions: Less- traumatizing actions during VBD have less harmful consequences and better perinatal outcome. Lower Apgar score was noted with the aggressiveness of the mode of VBD.
\end{abstract}

Key words: vaginal delivery; breech presentation; delivery mode; perinatal outcome

Ginekologia Polska 2022; 93, 9: 728-734

\section{INTRODUCTION}

Breech presentation occurs in 3-5\% of term newborn. While that percentile is higher for preterm newborns (about $20 \%$ of newborns), vaginal delivery of breech presentation (VBD) has been the tradition since the 1st century AD. Contemporary vaginal delivery of breech presentation began in the middle of the 20th century with Bracht who published a new method, which was named after him, with minimal interventions for delivering breeches [1]. After that, more and more research had begun in the field of minimal invasive methods in vaginal breech delivery. Later, Vermelin and Thiessen introduced the technique of passive breech management with spontaneous or supported VBD without obstetric intervention [2]. Known methods of delivery according to Müller, Bickenbach, Mauriceau- Lovret- Veit-Smellie and Lövset are used in case of hand and head retention $[3,4]$. The Term Breech Trial in 2000 showed a bad perinatal out- come and maternal outcome after VBD [5]. After that study, the number of caesarean deliveries increased rapidly in more countries. Recent studies show that there is no difference in perinatal outcome between vaginal and caesarean delivery [6]. Moreover, they show that elective caesarean delivery is related to abnormal immune response in a newborn, which could possibly explain why children and adults delivered by caesarean section are at greater risk of developing immune diseases and a long-term morbidity (Mb. Chron, allergic diseases, diabetes mellitus, attention deficit hyperactivity disorder (ADHD), autism, etc.) [7, 8]. Also, elective caesarean delivery increases the risk of maternal complications (bleeding, infection, thromboembolism) and complications in other pregnancies (invasive malplacentation, scar pregnancy, uterine rupture, hysterectomy) [9]. The aim of this study was to compare perinatal outcome depending on the mode of VBD.

\footnotetext{
Corresponding author:

Analena Gregorić

University Zagreb, School of Medicine Šalata 3, HR- 10000 Zagreb, Croatia

tel: +385992165601, e-mail: analena.gregoric@gmail.com
} 


\section{MATERIAL AND METHODS}

The perinatal outcomes of 98 VBD were reviewed retrospectively from 2005-2018 at the Department of Gynecology and Obstetrics, Clinical Hospital 'Sveti Duh', Zagreb.

Criteria for VBD at term pregnancy included:

- Normal pelvimetry;

- Ultrasonographical estimated fetal weight $(<3,800 \mathrm{~g})$;

- Completed or frank breech presentation;

- Absence of fetal and maternal comorbidity (gestational diabetes mellitus (GDM), hypertension, oligohydramnios, intrauterine growth restriction (IUGR));

- Fetal head flexion.

All deliveries were observed by a senior obstetrician and a pediatrician- neonatologist in the delivery room with continuous cardiotocographic (CTG) fetal monitoring. Pregnant women and newborns were divided into six groups depending on the mode of VBD used (Bracht, Müller, Thiessen, classic arm release, Mauriceau-Levret-Veit-Smellie (MLVS) and Vermelin). Also, the incidence of episiotomy, the course of labor (spontaneous, induced), maternal age and parity were observed. In perinatal outcome of newborns, birth weight and length of newborns, gestational age and an Apgar score at 1 and 5 minutes after delivery were observed. Statistical analysis made by Kruskal-Wallis test with a statistical value of $\mathrm{p}<0.001$ included a percentage calculation and a multivariant analysis.

\section{RESULTS}

During the period of 2005-2018, there were total of 1,510 singleton breech deliveries at the Department of Gynecology and Obstetrics Clinical Hospital "Sveti Duh". By caesarean section, 1,412 newborns were delivered while 98 newborns were delivered vaginally.

Twenty-three out of the 1,412 newborns delivered by caesarean section required transfer to neonatal intensive care unit (NICU). Most women in this group were $<35$ years (78\%). Also, most women were multiparas (71\%).

The most frequently used breech delivery mode during vaginal delivery was Thiessen (35.71\%), followed by MLVS (25.51\%), Bracht (22.45\%), Vermelin (13.27\%), classical arm release (2.04\%) and Müller technique (1.02\%).

Table 1 shows maternal demographic parameters (age and parity), the course of labor (spontaneous, induced) and the incidence of episiotomy depending on the mode of vaginal delivery. Seventy-point five percent of women included in the study were $\leq 35$ years of age, and $37.76 \%$ were multiparas. There is no statistically significant difference between the years or parity of pregnant women in groups of different methods of assistance during VBD. Seven-point fourteen percent of labors were induced because fetal growth restriction without hypoxia, uterine inertia in term pregnancy and oligohydramnios and the incidence of episiotomy was $63.27 \%$ with the top of incidence by Thiessen mode.

Table 2 shows perinatal outcomes depending on the mode of VBD. This includes birth weight and length, gestation age and an Apgar score at 1 - and 5-minute marks after labor. More than half of the newborns were born in term, 38-42 gestation week (65.31\%). Seventy-four-point forty-nine percent of newborns had a weight $>2,500 \mathrm{~g}$ and $47.96 \%$ had a length $46-50 \mathrm{~cm}$.

An Apgar score $>7$ at the 5 -minute mark had $100 \%$ of newborns delivered by Thiessen mode, $90.9 \%$ by Bracht, $76.00 \%$ by MLVS, $61.5 \%$ by Vermelin, $50 \%$ by classical arm release and $0 \%$ by Müller technique. There were $34.69 \%$ of preterm newborns delivered between 22-37 gestation week. The most preterm newborns were delivered by Thiessen (29.41\%) and MLVS technique (29.41\%) followed by Bracht (17.65\%), Vermelin (17.65\%), Müller (2.94\%) and classical arm release (2.94\%). Fifteen-point thirty-one per-

Table 1. Maternal demographic data

\begin{tabular}{|c|c|c|c|c|c|c|c|}
\hline & \multicolumn{6}{|c|}{ Delivery mode } \\
\hline & & Bracht & Thiessen & Müller & MLVS & Classical arm release & Vermelin \\
\hline Total of cases & 98 & $22(22.45 \%)$ & 35 (35.71\%) & $1(1.02 \%)$ & $25(25.51 \%)$ & $2(2.04 \%)$ & $13(13.27 \%)$ \\
\hline \multicolumn{8}{|l|}{ Maternal age } \\
\hline$\leq 35$ & $69(70.50 \%)$ & 14 & 26 & 1 & 20 & 2 & 6 \\
\hline$>35$ & $29(29.50 \%)$ & 8 & 9 & & 5 & & 7 \\
\hline \multicolumn{8}{|l|}{ Parity } \\
\hline nultipara & 37 (37.76\%) & 8 & 13 & 1 & 8 & 1 & 6 \\
\hline multipara & $61(62.24 \%)$ & 14 & 22 & & 17 & 1 & 7 \\
\hline \multicolumn{8}{|c|}{ Course of labor } \\
\hline spontaneous & & 22 & 30 & 1 & 23 & 2 & 13 \\
\hline Induced & & & 5 & & 2 & & \\
\hline Episiotomy & 62 (63.27\%) & 14 (63.64\%) & 26 (74.29\%) & $0(0 \%)$ & $18(72.0 \%)$ & $0(0 \%)$ & 4 (30.77\%) \\
\hline
\end{tabular}


Table 2. Perinatal outcome

\begin{tabular}{|c|c|c|c|c|c|c|}
\hline & \multicolumn{6}{|c|}{ Delivery mode } \\
\hline & Bracht & Thiessen & Müller & MLVS & Classical arm release & Vermelin \\
\hline \multicolumn{7}{|c|}{ Birth lenght, cm } \\
\hline$<40$ & 3 & 4 & 1 & 3 & 1 & 5 \\
\hline $41-45$ & & 3 & & 4 & & 1 \\
\hline $46-50$ & 13 & 21 & & 6 & 1 & 6 \\
\hline$>51$ & 6 & 7 & & 12 & & 1 \\
\hline \multicolumn{7}{|c|}{ Birth weight, $g$} \\
\hline 500-999 & 3 & 2 & 1 & & 1 & 4 \\
\hline $1000-1499$ & & 1 & & 4 & & 1 \\
\hline 1500-1999 & & 2 & & 1 & & 1 \\
\hline $2000-2499$ & 1 & 2 & & 1 & & \\
\hline$>2500$ & 18 & 28 & & 19 & 1 & 7 \\
\hline \multicolumn{7}{|c|}{ Gestational age, week } \\
\hline $22-28$ & 2 & 3 & 1 & 3 & 1 & 5 \\
\hline 29-32 & & & & 3 & & 1 \\
\hline $33-37$ & 4 & 7 & & 4 & & \\
\hline $38-42$ & 16 & 25 & & 15 & 1 & 7 \\
\hline \multicolumn{7}{|l|}{ Apgar score } \\
\hline $1 \min >7$ & 17 & 30 & & 13 & 1 & 7 \\
\hline $1 \min \leq 7$ & 5 & 5 & 1 & 12 & 1 & 6 \\
\hline $5 \min >7$ & 20 & 35 & & 19 & 1 & 8 \\
\hline $5 \min \leq 7$ & 2 & & 1 & 6 & 1 & 5 \\
\hline
\end{tabular}

cent $(15 / 98)$ of all included newborns were transferred to the NICU, all who had an Apgar score $\leq 7$ at the 5-minute mark. Fourteen out of 15 newborns transferred to NICU were preterm. Most newborns transferred to NICU were delivered by MLVS (40\%).

With classical arm release, transfers of newborns to the NICU was 50\%, MLVS (24\%), Vermelin (38.46\%) and Bracht mode (9.09\%). Only one newborn transferred to the NICU was a term. It was delivered by the Bracht method. Reason for a low Apgar score in 5 minutes was a result of complicated obstetrics techniques (MLVS, Müller, classical arm release) and early maladaptation. All other newborns were preterm, and it is an increased risk for a necessary transfer to the NICU.

Higher Apgar scores and less transfers to the NICU were noticed with less-traumatizing assistance during VBD. 100\% of the newborns delivered by the Thiessen mode required no other treatment. The percentage decreased in other more active delivery modes $(p<0.001)$ and the lowest was through delivery by the Müller technique.

During vaginal delivery, intrapartum complications (impossible head extraction, cervical spasm, the use of forceps, umbilical prolapse, etc.) or traumatic injury to newborns (intracranial hemorrhage, musculoskeletal lesion, bone fracture, etc.) were not recorded.

\section{DISCUSSION}

In 2002, there was a trend in the US and EU to perform caesarean delivery for term singleton fetus in a breech presentation [10]. Eighty-six-point nine percent of newborns in the United States were delivered by elective caesarean section. According to that, the number of obstetricians with experience and skills required to VBD has reduced. This problem is also present in major medical clinics where education is conducted because there is not enough VBD which would enable an adequate education of future obstetricians [11].

The trend related to the increased number of elective caesarean sections in breech presentation has initiated by the major international multicenter randomized clinical trial published by the Canadian obstetricians (Term Breech Trial Collaborative Group) in 2000 [5]. The study included 2088 pregnant women in 121 institutions from 26 countries. Their results showed a higher risk of neonatal mortality and morbidity in vaginal delivery compared to elective caesarean section. Considering its size and controlled implementation, this study is somewhat revolutionary when 
it comes to the current attitude towards delivery in breech presentation.

After a few years, additional publications have been written that modify the original conclusions of the 2000 Term Breech Trial [6]. The same researchers have published three follow-up studies with maternal outcomes at three months after delivery and children's' outcomes two years after labor. Those studies showed that the risk of urinary incontinence was lower for women in the planned caesarean delivery group at three months postpartum, and after two years, there was no difference between the groups. Furthermore, at two years postpartum, most women $(79.1 \%)$ did not report a difference in most maternal parameters, including breastfeeding, menstrual problems, depression, pain and distressing memories of the birth experience. Also, the studies showed that there was no difference in the risk of death or neurological damages between the elective caesarean group and the planned vaginal delivery group. Goffinet et al., concluded that different countries have different obstetric practices and there are better outcomes in vaginal delivery in the country where that mode is used more often [12-14].

In 2018, The American College of Obstetricians and Gynecologists made the following recommendations for the VBD [11]:

- Obstetrician-gynecologists and other obstetric care providers should offer external cephalic version as an alternative to planned caesarean for a woman who has a term singleton breech fetus, and she has no contraindications for that. In that case caesarean delivery services must be readily available;

- The decision regarding the mode of delivery should consider patient wishes and the experience of the health care provider;

- Planned VBD of a term singleton breech fetus may be reasonable, but under specifical guidelines;

- IfVBD is planned, a detailed informed consent should be documented - including risks that perinatal or neonatal mortality and short-term neonatal morbidity may be higher than if a caesarean delivery is planned.

The VBD can be recommended if certain criteria are met. Consistent international recommendations are still missing, so several different characteristics are used as exclusion criteria for vaginal planned breech deliveries $[15,16]$. Criteria for planned vaginal breech delivery at term pregnancy included the expected normal vaginal delivery, ultrasonographic estimated fetal weight $<3,800 \mathrm{~g}$, fetal head flexion, normal pelvimetry of a maternal pelvis, absence of a comorbidity (hypertension, gestational diabetes mellitus, intrauterine growth restriction, oligohydramnios), completed or frank breech presentation, a term pregnancy (38-42 gestation week) and the educated obstetrician. Also,
The English breech guideline uses a birth weight of 3,800 $\mathrm{g}$ or more as an indication for a cesarean section. Contraindications for planned vaginal delivery in breech presentation include [17-19]:

- Cord - breech presentation (compound presentation);

- Footling breech presentation (1 or both hips extended);

- Fetal growth restriction or macrosomia (newborn weight more than 4,000 g);

- Fetal anomaly likely to interfere with vaginal labor;

- Fetal head - hyperextended;

- Clinically inadequate maternal pelvis.

Recent studies have suggested possible association of immunological diseases such as asthma, inflammatory bowel disease, type 1 diabetes in children born by caesarean section $[7,8]$. Moreover, a maternal 6 morbidity after a caesarean section is three times higher than after vaginal delivery. Also, long- term neurological infant outcomes (including cerebral palsy) do not differ by planned vaginal delivery or caesarean section. Keag et al. [19], and authors in their meta-analysis and systematic review described that there is no statistically significant association of mode of delivery with perinatal mortality. Their meta- analysis described eight studies showing an association between allergies, hypersensitivity, dermatitis, or atopic conditions with cesarean section. Caesarean section was also associated with increased odds of childhood obesity up to five years when compared with vaginal delivery. Also, their research shows many disadvantages of caesarean section for further pregnancy and labor such as increased odds of placenta previa, placental abruption, ectopic pregnancy and increased odds of miscarriage or hysterectomy. The mechanics of VBD pose a greater risk of perinatal injury than caesarean section, but short- term injury often resolves and reliable estimates of permanent damage are lucking [20]. A newborn in breech presentation has a higher risk of cord presentation and a higher risk of cord prolapse during delivery than a newborn in cephalic presentation. That risk varies from $<1 \%$ to $10 \%$ and is higher for so-called "footling breech presentation" [21]. As mentioned, footling breech presentation is indication for caesarean section. But a fetus with feet presentation with flexed hips and flexed knees is known as a complete breech. Also, an incomplete breech is a fetus with flexed hips, one extended knee and one flexed knee. Both, fetus in completed breech and in incomplete breech presentation are qualified for VBD [22].

A retrospective cohort study published by Finnish authors compare neonatal and maternal outcomes in spontaneous onset preterm VBD after trial of labor (BTOL) and elective caesarean section (BCS) and between BTOL and vertex control deliveries, in singleton fetuses at $32+0-36+6$ weeks of gestation [20]. Results showed that no mortality was observed and severe morbidity was rare. 
Sixteen-point five percent of neonates in the BLOT group, $23.3 \%$ in the BCS group and $7.8 \%$ in the vertex control group needed support after delivery in the neonatal intensive care unit (NICU). Lower gestation age and small for gestation age were associated with the need for support in the NICU. This study showed that maternal morbidity was similar across the groups. Median blood loss was more pronounced in the BCS group compared to the BTOL group. So, in breech deliveries at $3+0-36+6$ gestational weeks, BTOL did not increase neonatal morbidity compared to BCS $[23,24]$. Our study included 14 preterm newborns who were transferred to NICU. Twelve out of 14 were extremely premature and they were delivered due to some complications (placenta defects, abruptio placentae, preterm premature rupture of membranes (PPROM), anhydramnios). All newborns transferred to NICU, independent of gestational age, survived and were discharged from NICU.

Minimal assistance delivery is used in vaginal delivery in breech presentation. With some method of minimal assistance delivery it was possible to successfully complete $70 \%$ of the breech presentation. In case of some complications, the newborn should be delivered by some method for the release of the head and/or shoulder or by a caesarean section. As shown in our study, delivery by Thiessen had the best perinatal outcome. Also, the most newborns transferred to NICU were delivered by MLVS technique. It shows that the more traumatizing method being used, the worse perinatal outcome and more transfers to NICU result. Also, most vaginal delivery in breech presentation is uncomplicated and can be completed with no assistance (Vermelin) or with minimal assistance at delivery (Thiessen). Such cases are highest at vaginal delivery in breech presentation. Sometimes complications occur, such as stagnation of the shoulder or the head, and more complicated methods are needed. Fortunately, this is not very common. This is why there is such a difference in the number of the deliveries with different delivery modes. Unfortunately, the difference in the number of deliveries between groups may be increasing the likelihood of a mistake. So, this study should be compared with other such studies. $[25,26]$. The best conclusion would be made by meta- analysis of all study that research vaginal delivery in breech presentation.

In 2016, Louwen et al., and a group of authors published study about perinatal outcomes in breech presentation depending on maternal position during the delivery (upright, on their back or caesarean section). Results showed a non - significant increased risk of mortality and serious morbidity for planned vaginal deliveries in the maternal dorsal position, but much smaller differences in risk with upright delivery, or planned vaginal birth ending in caesarean, when compared with planned caesarean. Also, with the mother in an upright position then in a dorsal position the length of second stage of vaginal delivery was significantly shorter $-42 \%$ shorter. The study compared the first years of research, then the dorsal position was used almost $1 / 3$ of the time and the last 2.5 years of study, when all VBD were done upright - the comparison shows the caesarean rate reduced by $32 \%$. Researchers from Austria did an analysis limited to 41 VBD with the woman on her hands and knees and after that a retrospective cohort of classic VBD. They concluded that upright delivery seemed to be "safe for the fetus with reduced maternal morbidity". According to that, VBD in the upright position was associated with shorter second stages, reduced maneuvers and neonatal injuries, less serious perinatal laceration than was the dorsal position, less caesareans during labor, suggesting potential advantages of maternal upright position for $\operatorname{VBD}[27,28]$. Vaginal delivery in breech presentation in a position other than a dorsal position also requires obstetric care providers with a lot of a knowledge and an experience. So, that is only implement in some European centers.

Induction of labor in breech presentation has rarely, but recently, been reported. Finnish authors published a retrospective observational study of induction of labor in breech presentation [29]. Results showed no statistical differences between the induction group and the spontaneous group regarding neonatal and maternal morbidity and mortality. Indications for induction are diverse: delayed labor after spontaneous rupture of membranes, preeclampsia, postterm pregnancy, diabetes, etc. The labor can be induced with prostaglandins, a balloon catheter, an oxytocin infusion and an amniotomy. The mode of induction has no effect the success rate of the VBD. In the study published by Finnish obstetricians, they observed two groups of deliveries: in the induction group the second stage of delivery was significantly longer, furthermore there were more cases of diabetes, and the gestation age was higher in that group of deliveries. The study also showed that the induction of labor was not associated with an increased risk of neonatal morbidity. The vaginal delivery rate in induction VBD at term is like the rate of induced deliveries with the fetus in cephalic presentation. Another group of obstetricians compared the induction of labor with the elective caesarean section. Results showed that there was no significant difference between the groups for the primary neonatal outcome in the planned caesarean section versus in the induction of labor. Consequently, the induction of labor might be an additional tool after unsuccessful external version to prevent a primary caesarean section [29-31].

In 2018, study in Australia and New Zealand showed that experience and confidence in VBD increased with the number of procedures performed and were significantly higher among Fellows [32]. Despite the level of confidence, 
responders felt confidence in managing vaginal twin delivery more than managing vaginal breech deliveries, and only $32.7 \%(67 / 205)$ of respondents intended to offer vaginal breech delivery in their practice. The main reasons reported were the risk of adverse outcomes and potential medicolegal consequences (43.4\%) and not enough experience (57.2\%). The encouragement of older obstetricians, more practice and an adequate birth room are necessary to young obstetrician- gynecologist fore achieves self- confidence in managing vaginal delivery in breech presentation.

The Swiss clinical study implements VBD in its clinical guidelines, naming that the renaissance in delivery in breech presentation [33]. Our study shows that the newborns delivered by Thiessen and Bracht method had the best perinatal outcomes. These two methods are also referred in other studies as the two methods of assistance with the best perinatal outcome. The method of assistance has direct impact on the perinatal outcome in $\mathrm{VBD}$, regardless of a parity and a gestation age, and better outcomes are related with less-traumatizing methods. Also, obstetricians and obstetric care providers with enough experience and knowledge are indispensable.

The results of our study showed that the better perinatal outcome of newborns was during vaginal delivery by Thiessen method compared to other methods of assistance during vaginal delivery. Also, very good outcomes were at newborns delivered by Vermelin and Bracht methods. Those three methods are methods with minimal assistance, and it brings a lot of benefit during vaginal delivery in breech presentation. Sixty-four out of 98 pregnancies were completed between 38 and 42 gestation weeks.

Comparing percentages of newborns who were transferred to NICU, the number is higher in VBD. On the other hand, 14/15 newborns delivered vaginally who were transferred were preterm and that was additional 8 reason for transfer to the NICU. With caesarean section, 20/23 newborns who were transferred to the NICU were preterm. The most common condition in NICU transfer in vaginal delivery were placenta defects, abruptio placenta, PPROM, anhydramnion and polyhydramnion while in caesarean section these were preeclampsia, placenta defects, Rh-immunization and hypoxio detalis.

Following the criteria for VBD is not necessarily planned elective caesarean section in pregnancy with fetus in breech presentation. Perinatal outcome, as show in this study and in many other studies, does not differ between caesarean section and vaginal delivery. Better outcomes were detected at newborns delivered vaginally by method with minimal assistance. These results indicate that the assisted delivery technique has an impact on perinatal outcome of newborns delivered by vaginally.

\section{CONCLUSIONS}

According to our study, it is necessary to know that better outcomes are related to less- traumatizing methods of assistance. Some recommendation for vaginal breech delivery needs to be followed for the best perinatal outcome and a minimally maternal injury. To sum up, vaginal delivery in breech presentation (VBD) is a safe option in the centers where there is enough experience and knowledge among obstetric care providers.

\section{Statement of ethics}

This research has the approval of an Ethics Review Committee.

\section{Conflict of interest}

The authors have no conflicts of interest to declare.

\section{Funding}

The authors declare no source of funding.

\section{REFERENCES}

1. Plentl AA, Stone RE. The Bracht maneuver. Obstet Gynecol Surv. 1953; 8(3): 313-325, indexed in Pubmed: 13063801.

2. Thiessen P. Die eigene Geburtsleitung bei Beckenendlage und ihr Gegensatz zur Schul-und Lehrauffassung. Geburtshift Frauenheik. 1964; 24: 661-667.

3. Dudenhausen JW, Pschyrembel W. Praktische Geburtshilfe. Walter de Gruyter, Berlin 2001.

4. Büscher U, Dudenhausen JW. Lageanomalien des Fetus in der Schwangerschaft: Beckenendlage. Der Gynäkologe. 2002; 35(1): 69-80, doi: 10.1007/pl00003302.

5. Hannah ME, Hannah WJ, Hewson SA, et al. Planned caesarean section versus planned vaginal birth for breech presentation at term: a randomised multicentre trial. Term Breech Trial Collaborative Group. Lancet. 2000; 356(9239): 1375-1383, doi: 10.1016/s0140-6736(00)02840-3, indexed in Pubmed: 11052579.

6. Whyte H, Hannah ME, Saigal S, et al. Term Breech Trial Collaborative Group.. Outcomes of children at 2 years after planned cesarean birth versus planned vaginal birth for breech presentation at term: the International Randomized Term Breech Trial. Am J Obstet Gynecol. 2004; 191(3): 864-871.

7. Sevelsted A, Stokholm J, Bønnelykke K, et al. Cesarean section and chronic immune disorders. Pediatrics. 2015; 135(1): e92-e98, doi: 10.1542/peds.2014-0596, indexed in Pubmed: 25452656.

8. Cho CE, Norman M. Cesarean section and development of the immune system in the offspring. Am J Obstet Gynecol. 2013; 208(4): 249-254, doi: 10.1016/j.ajog.2012.08.009, indexed in Pubmed: 22939691.

9. Jennewein L, Kielland-Kaisen U, Paul B, et al. Maternal and neonatal outcome after vaginal breech delivery at term of children weighing more or less than $3.8 \mathrm{~kg}$ : A FRABAT prospective cohort study. PLoS One. 2018; 13(8): e0202760, doi: 10.1371/journal.pone.0202760, indexed in Pubmed: 30138358.

10. Martin JA, Hamilton BE, Sutton PD, et al. U.S. Department of Health and Human Services Centers for Disease Control and Prevention. Births: preliminary data for 2002. Natl Vital Stat Rep. 2003; 51(11): 1-20, indexed in Pubmed: 12848421.

11. ACOG Committee opinion No. 745 summary: Mode of term singleton breech delivery. Obstet Gynecol. 2018; 132(2): 531-532, doi: 10.1097/AOG.0000000000002756, indexed in Pubmed: 30045205.

12. Goffinet F, Carayol M, Foidart JM, et al. PREMODA Study Group. Is planned vaginal delivery for breech presentation at term still an option? Results of an observational prospective survey in France and Belgium. Am J Obstet Gynecol. 2006; 194(4): 1002-1011, doi: 10.1016/j.ajog.2005.10.817, indexed in Pubmed: 16580289. 
13. Alarab M, Regan $C, \mathrm{O}^{\prime}$ Connell MP, et al. Singleton vaginal breech delivery at term: still a safe option. Obstet Gynecol. 2004; 103(3): 407-412, doi: 10.1097/01.AOG.0000113625.29073.4c, indexed in Pubmed: 14990399.

14. Giuliani A, Schöll WMJ, Basver A, et al. Mode of delivery and outcome of 699 term singleton breech deliveries at a single center. Am J Obstet Gynecol. 2002; 187(6): 1694-1698, doi: 10.1067/mob.2002.127902, indexed in Pubmed: 12501085.

15. Ghosh MK. Breech presentation: evolution of management. J Reprod Med. 2005; 50(2): 108-116, indexed in Pubmed: 15755047.

16. Gifford DS, Morton SC, Fiske M, et al. A meta-analysis of infant outcomes after breech delivery. Obstet Gynecol. 1995; 85(6): 1047-1054, doi: 10.1016/0029-7844(95)00053-T, indexed in Pubmed: 7770253.

17. St Saunders NJ. Controversies: the mature breech should be delivered by elective cesarean section. J Perinat Med. 1996; 24(6): 545-551, doi: 10.1515/jpme.1996.24.6.545, indexed in Pubmed: 9120737.

18. Kallianidis AF, Schutte JM, van Roosmalen J, et al. Maternal Mortality and Severe Morbidity Audit Committee of the Netherlands Society of Obstetrics and Gynecology. Maternal mortality after cesarean section in the Netherlands. Eur J Obstet Gynecol Reprod Biol. 2018; 229: 148-152, doi: 10.1016/j.ejogrb.2018.08.586, indexed in Pubmed: 30195138.

19. Keag O, Norman J, Stock S. Long-term risks and benefits associated with cesarean delivery for mother, baby, and subsequent pregnancies: Systematic review and meta-analysis. PLOS Medicine. 2018; 15(1): e1002494, doi: 10.1371/journal.pmed.1002494.

20. Kotaska A, Menticoglou S. No. 384-Management of breech presentation at term. J Obstet Gynaecol Can. 2019; 41(8): 1193-1205, doi: 10.1016/j. jogc.2018.12.018, indexed in Pubmed: 31331608

21. Cunningham FG, Leveno KJ, Bloom SL. Williams Obstetrics 22nd ed. MCGraw- Hill, New York 2005.

22. Feige A, Krause M. Beckenendlage [Breech]. Urban \& Schwarzenberg, Munich 1998.

23. Toivonen $\mathrm{E}$, Palomäki $\mathrm{O}$, Korhonen $\mathrm{P}$, et al. Impact of the mode of delivery on maternal and neonatal outcome in spontaneous-onset breech labor at 32-36 weeks of gestation: A retrospective cohort study. Eur J Obstet Gynecol Reprod Biol. 2018; 225: 13-18, doi: 10.1016/j. ejogrb.2018.03.054, indexed in Pubmed: 29626709.
24. Hinnenberg $\mathrm{P}$, Toijonen A, Gissler M, et al. Outcome of small for gestational age-fetuses in breech presentation at term according to mode of delivery: a nationwide, population-based record linkage study. Arch Gynecol Obstet. 2019; 299(4): 969-974, doi: 10.1007/s00404-019-05091-2, indexed in Pubmed: 30734863.

25. Habek D. Minimally assisted breech delivery. Gynecol Perinatol. 2009; 18(1): 17-22.

26. Vranjes $\mathrm{M}, \mathrm{Habek} D$. Perinatal outcome in breech presentation depending on the mode of vaginal delivery. Fetal Diagn Ther. 2008; 23(1): 54-59, doi: 10.1159/000109227, indexed in Pubmed: 17934299.

27. Louwen F, Daviss BA, Johnson KC, et al. Does breech delivery in an upright position instead of on the back improve outcomes and avoid cesareans? Int J Gynaecol Obstet. 2017; 136(2): 151-161, doi: 10.1002/ijgo.12033, indexed in Pubmed: 28099742.

28. Bogner G, Strobl M, Schausberger C, et al. Breech delivery in the all fours position: a prospective observational comparative study with classic assistance. J Perinat Med. 2015; 43(6): 707-713, doi: 10.1515/jpm-20140048, indexed in Pubmed: 25204214.

29. Gaillard T, Girault A, Alexander $\mathrm{S}$, et al. Is induction of labor a reasonable option for breech presentation? Acta Obstet Gynecol Scand. 2019; 98(7): 885-893, doi: 10.1111/aogs.13557, indexed in Pubmed: 30723903.

30. Macharey G, Ulander VM, Heinonen S, et al. Induction of labor in breech presentations at term: a retrospective observational study. Arch Gynecol Obstet. 2016; 293(3): 549-555, doi: 10.1007/s00404-015-3853-4, indexed in Pubmed: 26315470.

31. Rojansky N, Tsafrir A, Ophir E, et al. Induction of labor in breech presentation. Int J Gynaecol Obstet. 2001; 74(2): 151-156, doi: 10.1016/s00207292(01)00424-6, indexed in Pubmed: 11502294.

32. Yeoh SGJ, Rolnik DL, Regan JA, et al. Experience and confidence in vaginal breech and twin deliveries among obstetric trainees and new specialists in Australia and New Zealand. Aust N Z J Obstet Gynaecol. 2019; 59(4): 545-549, doi: 10.1111/ajo.12931, indexed in Pubmed: 30565217.

33. Ribeiro K, Sichitiu J, Meuwly JY, et al. [The breech comeback: implementation of a vaginal delivery protocol in the CHUV]. Rev Med Suisse. 2018; 14(624): 1888-1892, indexed in Pubmed: 30375789. 